\title{
Medicine outside the clinic: the growing need for physicians in sexual education policy
}

Zachary Sanford, MSIV ${ }^{1}$

\section{Author Affiliations:}

1. Joan C. Edwards School of Medicine, Marshall University, Huntington, West Virginia

The author does not have any stated or potential conflicts of interest and has received no financial incentive for this publication.

Corresponding Author:

Zachary Sanford, MSIV

Joan C. Edwards School of Medicine

Marshall University

Huntington, West Virginia

Email: sanford12@marshall.edu 


\begin{abstract}
Sex and sexuality are both topics of immense social and personal importance, owing their openness or constraint in large part to the society in which they are discussed. In homogenous groups it may be possible to reach firm consensus on what is, or is not, appropriate to consider a sexual norm and use an overarching set of religious or spiritual morals to reaffirm this decision. However, in western society and specifically in the United States, a theme of integration and amalgamation of wildly different cultures has presented an interesting case study in searching for common ground on basic social issues. Notable amongst these is the question of sexual education and the role of government, religion, and family in determining the way and extent to which information is presented to individuals during their formative years. However, suspiciously absent in these discussions is the role of trained medical practitioners in vetting these curricula and participating in the education process.
\end{abstract}

\title{
Keywords
}

sex, education, ethics, opinion

\section{When I was Your Age: A Brief History of Sex Education in America}

Efforts to educate American populations on matters pertaining to sexual health, disease transmission and contraceptive techniques date back to the early twentieth century when women such as Margret Sanger and Emma Goldman began championing women's sexuality in public forums. ${ }^{1}$ These positions were met with staunch opposition, Sanger being imprisoned in 1916 for opening a clinic in Brooklyn that distributed contraceptive devices to working-class women ${ }^{2}$ and Goldman, a nurse by training, even being deported for her public speeches on contraceptive use ${ }^{3}$. This attitude of public sexual repression continued into the 1970s by which time twenty states had specifically passed legislation prohibiting the teaching of topics pertaining to sex or sexuality in public schools. ${ }^{4}$ This environment of intentionally withholding information would likely have continued indefinitely were it not for the human immunodeficiency virus (HIV)/acquired immunodeficiency syndrome (AIDS) pandemic of the 1980s. Hoping to reduce the number of HIV infections and ultimately reduce the number of AIDS cases, state legislators began enacting HIV and sexually transmitted infection (STI) education programs at the public school level. ${ }^{4}$ The Centers for Disease Control (CDC) went so far as to offer financial and technical assistance to programs in order to adequately educate the public. ${ }^{4}$ The precedent had been set in the United States: on matters pertaining to sexual health, medical experts were those the country turned to for guidance when it was most important.

Today the current number of states required by law to offer instruction on HIV/AIDS includes thirty-three states and the District of Columbia, although only twenty-two states and the District of Columbia are required to offer instruction on sexual education. ${ }^{5,6}$ While it seems the lessons from the AIDS pandemic have left a legacy on the current state of sexual education ${ }^{7}$, it is interesting to note that of the states required to offer sexual education, nineteen mandate that "sex education must be medically, factually or technically accurate" . Among these definitions for accuracy, one includes offering a curriculum based on "published authorities upon which medical professionals rely". ${ }^{6}$ It appears that there is a subset of the country that demonstrably relies on medical knowledge for educational purposes when it comes to matters of sex education. 


\section{More than Just a White Coat: A Physician's Obligation to His Patients}

Western medicine has a long tradition dating as far back as the $5^{\text {th }}$ century BCE, to which the first recorded documentation of the Hippocratic Oath can be attributed. ${ }^{8}$ This oath, sworn by over $98 \%$ of American physicians upon graduation from medical curricula across the country ${ }^{8,9}$, outlines in poignant language the responsibilities shouldered by one who chooses to practice medicine. Among this list includes one of the most inviolable of the physician's oaths, the promise that, "I will prescribe regimens for the good of my patients according to my ability and my judgment and never do harm to anyone". ${ }^{8}$ This call to exercise judgment on part of the physician inherently lends itself to ambiguity; what one physician finds prudent another may find wholly out of order. Still, it is on this oath that the near entirety of modern medical practitioners has sworn and it is to this standard that physicians are held accountable by their patients and by society as a whole.

Patients seek the advice of medical professionals with the understanding that these individuals are up-to-date on medical science. ${ }^{10-12}$ Gone are the days of paternalism, wherein a physician would do only what was seen fit and minimalize patient involvement in making healthcare decisions. Modern practice focuses on the idea of discussing alternatives with explanations of advantages and disadvantages afforded by each option. ${ }^{13}$ Patients expect that their doctor will be able to summarize a wealth of complex biological, chemical, and epidemiological data into small, easy to understand snippets from which they are able to draw meaningful conclusions. ${ }^{14}$ Sexual health and education, areas directly contributing to public health and patient well-being, are no different.

Clinical recommendations for sexual counseling have been well-documented elsewhere ${ }^{15,16}$ and lists the need to, among other practices, screen sexually active adolescent females for chlamydia, gonorrhea, and to refer adolescent males and females to sex education programs at their local schools, faith-based organizations, and community groups ${ }^{17-20}$. However there have been studies focused on direct physician-led instruction in patient education that have yielded favorable outcomes, including increasing safe sex practices, discussing number of sexual partners, and disclosing STI infection status with active and past partners. ${ }^{21-26}$ These measures directly impact patient behavior ${ }^{21,22,27,28}$, and by extension have positive effects on public health at the individual and group level ${ }^{23,26}$. This illustrates that while physicians may not be an exclusive source for patient education, they should not necessarily be excluded as a possible resource.

\section{The Modern Renaissance Doctor: The Role of Physicians Outside of Patient Treatment}

Healthcare is a continued subject for political discourse, representing $17.9 \%$ of the current American gross domestic product and showing no signs of decreasing. ${ }^{29}$ At the national level, healthcare policy shapes the quality of care received by the elderly, the impoverished and disabled, and the military with the Medicare, Medicaid, and the Veterans Administration programs, respectively. More recently healthcare policy has been brought under review with the passage of the Affordable Care Act, legislation that directly impacts the quality of care the physician is able to provide for all patients. While this legislation is drafted by politicians, they relied heavily on physicians for consultation regarding its intent and scope. President Obama first sought the healthcare industry through reaching out to physicians groups in order to gain support for the Affordable Care $\mathrm{Act}^{30}$, and was ultimately successful in signing this legislation into law. 
Furthermore, a growing number of physicians are themselves entering the political arena. Presently there are twenty physician members of the $113^{\text {th }}$ Congress, with three serving as Senators, sixteen serving as Representatives, and one delegate. ${ }^{31}$ Others choose more indirect routes such as joining the American Medical Association, one of the largest lobbying groups in the nation with regards to topics of medicine and politics. ${ }^{32}$ Through such special interest groups physicians are already impacting the direction of national healthcare policy, basing their claims on peer-reviewed literature and empirical data while providing a democratic forum in which medically educated individuals are able to express their opinions amongst peers. Using a rational, science-based approach, these institutions are handling delicate social issues with no clear, objective component in a way that maximizes patient autonomy and choice. ${ }^{33}$ In so doing, these physicians are upholding their oath to non-malfeasance and beneficence by recommending what is demonstrably proven in the literature while reaching a consensus on shared morality.

In this regard, abstinence only education is at odds with the openness and democratic principles promoted by these physician groups. Current abstinence only education is by definition exclusive ${ }^{4,34}$, requiring that individuals not only refrain from heterosexual intercourse but are by some extreme examples even asked to refrain from handholding ${ }^{34}$. This inherently reduces choice and is in many respects a clear example of medical paternalism. By refraining from discussing alternative courses of treatment and prevention, physicians are preventing access to information that can directly impact quality of life. ${ }^{34}$ At an institutional level, enacting policies that prevent the discussion of sexual health with patients remove physician discretion and have been linked to reduced efficacy of education programs both at the undergraduate medical, graduate medical, and clinical levels. ${ }^{35-38}$ Patient populations need access to educated and wellinformed physicians who are able to address concerns candidly and with the best information available. Although abstinence only education offers some degree of measurable benefit ${ }^{39}$ it is by no means exclusive $e^{4,17,19,21,34,37}$. Practitioners armed with a wide array of information are able to present alternatives in addition to abstinence only education that are in best agreement with the idea of partnership in patient treatment. ${ }^{40,41}$ By offering as much information as possible, including patient education by physicians, the patient population is more likely to make wellinformed decisions ${ }^{19,27}$ based on accurate knowledge and their own personal morality.

\section{Take Two and Call Me in the Morning: Future Directions of Physicians in Sex Education}

Medical practitioners have been asked to play a role in helping to educate the patient population on a number of social issues, ranging from the growing obesity epidemic ${ }^{42}$ to encouraging smoking cessation $^{43}$. These issues have been met with varying degrees of success. For example, smoking education programs and cessation courses offered in-hospital are encouraged by clinicians and have been linked to the dropping rate of lung cancer. ${ }^{44}$ If physician-led sexual education is to match the successes seen elsewhere, it must be met with more robust education at the undergraduate medical, graduate medical, and clinical levels.

The Liaison Committee on Medical Education (LCME) has made great efforts to standardize the curricula of undergraduate medical education across the country such that graduating medical students are equipped with the medical knowledge necessary to theoretically succeed in their desired medical subspecialty. ${ }^{38,45}$ However, glaringly absent or at best diminished among these 
curricula is a unified approach to discussing topics of sexuality, with anywhere between $42 \%$ and $62 \%$ of surveyed medical students finding their training in school to be insufficient for clinical practice. ${ }^{35,45-47}$ Admittedly, education efforts are best directed at primary care physicians who will have greater exposure to broad patient populations. This raises the question of which medical professionals are best-suited to benefit from additional sexual education. Areas for consideration include more discussion of sex and sexuality in the simulated patient environment and offering electives in sexual education. ${ }^{47}$

It is not the role of a physician to judge the morality of a patient but, rather, to use his medical knowledge and experience to guide the patient to make healthy and safe choices. While sex is sometimes considered a taboo subject in the United States, it is by no means any less relevant to patient health and wellbeing. If healthcare practitioners as a group are excluded from the education process, a valuable resource is lost to patients and further complicates an already complicated issue. It is the responsibility of the medical community to leave the option for practitioner-based sex education on the table as a tool to be used at the discretion of the physician and for the benefit of the patient. It is for these reasons that it is imperative that physicians utilize their education, training, and social standing to better educate patient populations in the area of sexual education. 


\section{References}

1. Muller-Jahncke WD. [Ludwig Haberlandt (1885-1932) and the development of hormonal contraception]. Z Gesamte Inn Med. 1988;43(15): 420-2.

2. About Margaret Sanger. Margaret Sanger Papers Project 2010 [cited 2013 September 30, 2013]; Available from: http://www.nyu.edu/projects/sanger/secure/aboutms/.

3. Isidori AMet al. Mechanisms in endocrinology: The spectrum of haemostatic abnormalities in glucocorticoid excess and defect. Eur J Endocrinol. 2015;173(3): R101-13.

4. Donovan P.School-based sexuality education: the issues and challenges. Fam Plann Perspect. 1998;30(4): 188-93.

5. Mayer R. 1996-97 trends in opposition to comprehensive sexuality education in public schools in the United States. SIECUS Rep. 1997;25(6):20-6.

6. Legislatures, N.C.o.S. State Policies on Sex Education in Schools. 2013 September 13, 2013 [cited 2013 September 30, 2013]; Available from: http://www.ncsl.org/issues-research/health/state-policies-on-sexeducation-in-schools.aspx\#1.

7. Blake SM et al. Local school district adoption of state-recommended policies on HIV prevention education. Prev Med. 2005;40(2): 239-48.

8. Dorman, J. The Hippocratic Oath. Journal of American College Health. 1995;44(2):84-88.

9. Sritharan KGR, Fritz Z, Wong D, Rollin M, Dunning J, Wayne B, Morgan P, Sheehan C. Medical oaths and declarations. BMJ. 2000;323(7327):1440-1.

10. Bener A, Ghuloum S. Gender difference on patients' satisfaction and expectation towards mental health care. Niger J Clin Pract. 2013;16(3): 285-91.

11. Kuzari D, Biderman A, and Cwikel J. Attitudes of women with breast cancer regarding the doctor-patient relationship. Eur J Cancer Care (Engl). 2013;22(5):589-96.

12. Pennbrant S. A trustful relationship--the importance for relatives to actively participate in the meeting with the physician. Int J Qual Stud Health Well-being. 2013;8:20608.

13. Weaver H. Partnership not paternalism. Nurs Times. 2013;109(27):25.

14. Chawla N, Arora NK. Why do some patients prefer to leave decisions up to the doctor: lack of self-efficacy or a matter of trust? J Cancer Surviv. 2013.

15. Ham P, Allen C. Adolescent health screening and counseling. Am Fam Physician. 2012;86(12):1109-16.

16. Salerno $\mathrm{J}$ et al. Identifying relationships between high-risk sexual behaviors and screening positive for chlamydia and gonorrhea in school-wide screening events. J Sch Health. 2013;83(2):99-104.

17. Anderson KM et al. Attitudes, experience, and anticipation of sex among 5th graders in an urban setting: does gender matter? Matern Child Health J. 2011;15 Suppl 1:S54-64.

18. Donaldson AAet al. Receipt of sexual health information from parents, teachers, and healthcare providers by sexually experienced U.S. adolescents. J Adolesc Health. 2013;53(2):235-40.

19. Chandra-Mouli V et al. Invest in adolescents and young people: it pays. Reprod Health. 2013;10(1):51.

20. Giorgio MM et al. Using chat and text technologies to answer sexual and reproductive health questions: planned parenthood pilot study. J Med Internet Res. 2013;15(9):e203.

21. Trieu SL, Bratton S, Marshak H. Sexual and reproductive health behaviors of California community college students. J Am Coll Health. 2011;59(8):744-50.

22. Markham CM et al. Sexual risk avoidance and sexual risk reduction interventions for middle school youth: a randomized controlled trial. J Adolesc Health. 2012;50(3):279-88.

23. Kimmel A et al. 'I make sure I am safe and I make sure I have myself in every way possible': AfricanAmerican youth perspectives on sexuality education. Sex Educ. 2013;13(2):172-185.

24. Ronis $\mathrm{T}$ et al. A pilot study of reproductive health counseling in a pediatric rheumatology clinic. Arthritis Care Res (Hoboken). 2013.

25. Cardom R, Rostosky S, Danner F. Does "It Get Better" for Depressed Sexual Minority Youth in Young Adulthood? J Adolesc Health. 2013.

26. Bachmann LH et al. Impact of a computer-assisted, provider-delivered intervention on sexual risk behaviors in HIV-positive men who have sex with men (MSM) in a primary care setting. AIDS Educ Prev. 2013;25(2):87-101.

27. Cavazos-Rehg PA, Krauss MJ., Spitznagel EL, Iguchi M, Schootman M, Cottler L, Grucza RA, Bierut LJ. Associations between sexuality education in schools and adolescent birthrates: a state-level longitudinal model. Arch Pediatr Adolesc Med. 2012;166(2):134-40. 
28. Nair MK et al. ARSH 1: Reproductive and Sexual Health Problems of Adolescents and Young Adults: A Cross Sectional Community Survey on Knowledge, Attitude and Practice. Indian J Pediatr. 2013.

29. Roberge $\mathrm{S}$ et al. Prevention of pre-eclampsia by low-molecular weight heparin in addition to aspirin: a meta-analysis. Ultrasound Obstet Gynecol. 2015.

30. Obama rallies doctors for health care reform. 2009.

31. Physicians of the 113th Congress. 2013.

32. Frick AP et al. Prediction of large for gestational age neonates: Screening by maternal factors and biomarkers in the three trimesters of pregnancy. Ultrasound Obstet Gynecol. 2015.

33. Harmon K. Obama calls on doctors at AMA meeting to set aside fears and support health reform. Scientific American. 2009.

34. Wilkerson A. I want to hold your hand: abstinence curricula, bioethics, and the silencing of desire. J Med Humanit. 2013;34(2):101-8.

35. Leiblum SR. An established medical school human sexuality curriculum: description and evaluation. Sexual and Relationship Therapy. 2001;16(1).

36. Schnarch DM,Jones K. Efficacy of sex education courses in medical school. J Sex Marital Ther. 1981;7(4):307-17.

37. Rhodes DL et al. Influence of professional preparation and class structure on sexuality topics taught in middle and high schools. J Sch Health. 2013;83(5)343-9.

38. Coleman E et al. Summit on medical school education in sexual health: report of an expert consultation. J Sex Med. 2013;10(4):924-38.

39. Najarkolaei FR et al. Promoting sexual abstinence intention among female university students: A quasiexperimental study. J Res Med Sci. 2013;18(1):37-43.

40. Obeidat RF, Homish GG Lally RM. Shared decision making among individuals with cancer in nonWestern cultures: a literature review. Oncol Nurs Forum. 2013;40(5):454-63.

41. von Puckler A. A patient's perspective of partnership in the treatment of multiple sclerosis: MS regimes-An orchestrated approach. J Neurol Sci. 2013.

42. Iannotti RJ, Wang J. Trends in Physical Activity, Sedentary Behavior, Diet, and BMI Among US Adolescents, 2001-2009. Pediatrics. 2013.

43. Kadanakuppe S, Aradhya S. Survey of patient opinion on tobacco cessation counseling and services in a dental teaching institution and hospital. Oral Health Prev Dent. 2013;11(2):175-80.

44. Niu X et al. Cancer survival disparities by health insurance status. Cancer Med. 2013;2(3):403-11.

45. Frank E, Coughlin SS, Elon L. Sex-related knowledge, attitudes, and behaviors of U.S. medical students. Obstet Gynecol. 2008;112(2 Pt 1):311-9.

46. Solursh DS et al. The human sexuality education of physicians in North American medical schools. Int J Impot Res. 2003;15 Suppl 5:S41-5.

47. Shindel AW, Parish SJ. Sexuality education in North American medical schools: current status and future directions. J Sex Med. 2013;10(1)3-17; quiz 18. 